\title{
Under-Five Mortality and Associated Risk Factors in Rural Settings of Ethiopia: Evidences from 2016 Ethiopian Demographic and Health Survey
}

\author{
Shewayiref Geremew Gebremichael (iD) and Setegn Muche Fenta \\ Department of Statistics, Debre Tabor University, Debre Tabor, Amhara, Ethiopia \\ Correspondence should be addressed to Shewayiref Geremew Gebremichael; shewger@dtu.edu.et
}

Received 24 December 2019; Revised 13 June 2020; Accepted 30 June 2020; Published 31 August 2020

Academic Editor: Jagdish Khubchandani

Copyright (C) 2020 Shewayiref Geremew Gebremichael and Setegn Muche Fenta. This is an open access article distributed under the Creative Commons Attribution License, which permits unrestricted use, distribution, and reproduction in any medium, provided the original work is properly cited.

\begin{abstract}
Background. Evidence shows that in Ethiopia, a gradual decrease of under-five mortality is observed, but it is still high in the rural settings of the country. We are motivated to investigate the socioeconomic, demographic, maternal and paternal, and child-related associated risk factors of under-five mortality given birth from rural resident mothers. Methods. Demographic and Health Survey data from Ethiopia (2016) were used for analysis. The chi-square test of association and logistic regression were used to determine the associated risk factors of under-five children mortality. Study Settings. Rural Ethiopia. Results. Secondary school and above completed fathers $(\mathrm{AOR}=0.77 ; 95 \% \mathrm{CI}: 0.63-0.94)$ and primary school completed mothers (AOR $=0.82 ; 95 \% \mathrm{CI}$ : $0.72-0.93$ ); multiple twin child $(\mathrm{AOR}=4.50$; 95\% CI: 3.38-5.98); public sector delivery ( $\mathrm{AOR}=0.65$; 95\% CI: 0.55-0.76); had working of mother $(\mathrm{AOR}=1.28 ; 95 \% \mathrm{CI}: 1.16-1.42)$ and of father $(\mathrm{AOR}=1.45 ; 95 \% \mathrm{CI}: 1.25-1.69)$; mothers aged above 16 at first birth $(\mathrm{AOR}=0.41 ; 95 \% \mathrm{CI}: 0.37-0.45)$; breastfeeding (AOR =0.60; 95\% CI: $0.55-0.66)$; birth order of $2-3(\mathrm{AOR}=1.18$; $95 \% \mathrm{CI}$ : 1.02-1.37); religious belief of Muslim $(\mathrm{AOR}=1.20$; 95\% CI: $1.02-1.41)$; users of contraceptive method (AOR =0.80; $95 \% \mathrm{CI}$ : $0.71-0.90)$; vaccinated child ( $\mathrm{AOR}=0.52$; 95\% CI: 0.46-0.60); family size of 4-6 ( $\mathrm{AOR}=0.74 ; 95 \% \mathrm{CI}: 0.63-0.86)$ and of seven and above $(\mathrm{AOR}=0.44 ;$ 95\% CI: 0.36-0.52); mother's age group: aged 20-29 (AOR=3.88; 95\% CI: 3.08-4.90), aged 30-39 $(\mathrm{AOR}=16.29 ; 95 \% \mathrm{CI}: 12.66-20.96)$, and aged 40 and above $(\mathrm{AOR}=55.97 ; 95 \% \mathrm{CI}: 42.27-74.13)$; number of antenatal visits: $1-3$ visits $(\mathrm{AOR}=0.50 ; 95 \% \mathrm{CI}$ : 0.43-0.58), and four and above visits ( $\mathrm{AOR}=0.46$; 95\% CI: 0.39-0.54); and preceding birth interval of 25-36 months ( $\mathrm{AOR}=0.55 ; 95 \% \mathrm{CI}$ : 0.48-0.62) and above 36 months ( $\mathrm{AOR}=0.30 ; 95 \% \mathrm{CI}: 0.26-0.34)$ are significant determinant factors of under-five mortality in rural settings. Conclusions. Differences in regions, educated parents, born in singleton, public sector delivery, nonavailability of occupation of parents, mothers older than 16 at first birth, breastfeeding, use of a contraceptive method, child vaccination, higher number of family size, repeated antenatal visits, and preceding birth interval play a significant role regarding the survival of under-five children. These, among other differences, should be addressed decisively as part of any upcoming strategic interventions to improve the survival of children in line with the target of 2030 Sustainable Development Goals (SDGs).
\end{abstract}

\section{Introduction}

Globally, since 2000, a $49 \%$ decline in the under-five mortality rate was recorded, indicates that over 50 million children's lives are saved [1]. More than 80 countries globally, specifically 69 of developing nations have reduced the under-five mortality by half since 2000 [2].

In 2018, 5.3 (5.1-5.7) million under-five children died, shows reduction from $12.5(12.4-12.7)$ million in 1990. The estimated rate of 93 (92-95) deaths per 1000 live births in 1990 reduced to 39 (37-42) deaths per 1000 live births in 2018, implies 1 in 11 children dying before reaching age 5 in 1990, while it is reduced to 1 in 26 in 2018, a 59 (55-60) percent decline $[3,4]$.

Chance of survival of children showed regional disparities, sub-Saharan Africa remains the region with the highest under-five mortality rate $[4,5]$, an average of 78 deaths per 1000 live births in 2018 ( 1 in 13 children dying 
before age 5), 16 times higher than the average ratio of 1 in 199 children in high-income countries. It is the home of $52 \%$ of all under-five deaths [4].

In Ethiopia, the maternal and newborn health coverage indicators show that in rural areas, $14 \%$ of women had made at least 4 antenatal care (ANC) visits compared to $46 \%$ in urban areas. Coverage of skilled attendance at birth is $5 \%$ in rural areas, while it is $52 \%$ in urban areas; at the national level, it was estimated on average $10.8 \%$. Regarding geographical regions, the region with the highest coverage of skilled birth attendance is Addis Ababa with $84 \%$ and the lowest coverage is Afar with 7\%, a difference of nearly 12 times [6].

Ethiopia has made significant progress towards improving the health of children and might achieve its Millennium Development Goal (MDG) 4 target (to reduce child mortality) in 2013. The reductions of child mortality are associated with improved coverage of effective interventions to prevent or treat the main cause of mortality, specifically immunizations, birth spacing, and early and exclusive breastfeeding, and with improvements in socioeconomic conditions [7]. Despite the progress, Ethiopia has faced different challenges which provide the basis for the country's priorities to accelerate progress towards achieving MDGs and further improving child survival and development, which are as follows: low utilization of maternal healthcare services; including skilled attendants at birth; high unmet need for family planning (FP); adolescent and youth sexual and reproductive health; awareness of healthy behaviors; cultural barriers; inequalities in health service utilization; and quality of care [7-9].

The survival status of children is one of the indicators of socioeconomic development of any given country, even if most developing countries are unable to tackle the causes of child morbidity and mortality due to the availability of poor public health measures and a lack of access to healthcare facilities [10].

According to the Ethiopia Demographic and Health Survey (EDHS) estimates of 2000 [11], 2005 [8], 2011 [9], and 2016 [12] child mortalities were higher in the rural parts of the country, where more than $80 \%$ of the country population lives in [13]. Differentials in child mortality among the rural and urban clusters imply the existence of difference in associated risk factors, based on where the child was born.

Even though different socioeconomic, demographic, maternal, and child-related risk factors were investigated on under-five child mortality, it was not clear yet presented on the clusters of populations among the rural and urban resident mothers. It is presented that the death of under-five was higher in rural residents than in urban, but in this study, the research questions are as follows: which risk factors (socioeconomic, demographic, maternal, and child-related) of getting death of under-five were higher among children from rural cluster populations? And what are the causes? We are motivated to investigate the different socioeconomic, demographic, maternal, and paternal characteristics, and birth-related and infant factors of under-five mortality given birth among rural resident mothers.

\section{Methods}

2.1. Study Setting. Ethiopia has a total landmass of $1,104,300 \mathrm{~km}^{2}$, of which $1,000,000 \mathrm{~km}^{2}(90.56 \%)$ is land area, and $104,300 \mathrm{~km}^{2}(9.44 \%)$ is covered by water bodies, with a population density of 102.37 per $\mathrm{km}^{2}$. The country is divided into 9 ethnically based regional states and 2 selfgoverning city administrations (namely, Tigray, Afar, Amhara, Oromia, Somali, Benishangul-Gumuz, SNNP, Gambela, Harari, Addis Ababa, and Dire Dawa). Addis Ababa is under the major urban population areas; the others are both urban and rural population divisions [14]. Populations in urban settings mean that peoples live in the areas of towns and cities (population higher than 2,000), while peoples who live in the areas of less than 2,000 populations are considered to be rural setting populations.

According to 2018 estimate, the total population of the country was above 108 million, which makes the country, the 12th rapid population growth in the world and the second most populous country in Africa, following Nigeria. The country is a predominantly agricultural based, more than $80 \%$ of the total population lives in the rural areas of the country. Ethiopia's rapid population growth is putting the country in an increasing pressure on the land resources, an increase of land degradation and deforestation, and an increase in scarcity of basic necessities such as food. Of the total population, about $43.21 \%$ are aged below 14 years, which are in a nonworking group. According to the 2018 estimate, the total population growth rate was $2.83 \%$, median age was 18.6 years, birth rate was 36 births per 1000 population, and death rate was 7.5 deaths per 1000 population. With regard to population distribution, the highest density is found in the highlands of the North and Middle areas of the country, particularly around the centrally located capital city of Addis Ababa; the Far East and Southeast are sparsely populated. Regarding urbanization, about $20.8 \%$ of the total population lives in urban areas. The use of contraceptive prevalence rate was $36.5 \%$ (based on the report of 2012). Drinking water source, about $93.10 \%$ of the population in urban areas used improved sources, while $6.9 \%$ used unimproved sources. About $27.2 \%$ of population who lives in urban areas used improved sanitation facility access, while $72.8 \%$ of population used unimproved sanitation facility (according to the 2015 estimate) [13].

In Ethiopia, under-five mortality shows a decline from 2000 to 2016, which were 166 deaths per 1000 live births in 2000 to 123 deaths per 1000 live births in 2005, and then 88 deaths per 1000 live births in 2011, and recently in 2016, it was 67 deaths per 1000 live births. This represents a 60\% decrease in under-five mortality over the period of 16 years. The under-five mortality also varies between urban and rural areas; under-five mortality is higher in rural areas (83 deaths per 1000 live births) than urban areas (66 deaths per 1000 live births), based on the ten year data prior to 2016 EDHS [12]. Regarding to residence, under-five mortality shows 17 deaths over difference in rural areas than in urban areas. This may be as researchers identified multiple risk factors for 
under-five mortality based on the characteristics of mothers and children, in some extent of fathers, and the different circumstances of birth and health-related factors were highly serious in rural areas than urban areas.

2.2. Data Sources. The study is based on secondary analysis of under-five mortality survey data obtained from the 2016 EDHS (2016 Ethiopian Demographic and Health Survey). The EDHS was organized in 2016 (January-June) by the Central Statistics Agency (CSA) of Ethiopia with the government of the country in collaboration with development partners through the technical assistance of ICF [12]. The EDHS survey target groups were age 15-49 male and female randomly selected households in all parts of the country, Ethiopia. Detailed information was collected on background characteristic of the respondents, fertility, marriage, fertility preference, awareness and the use of family planning methods, child feeding practices, nutritional status of women and children, adult and childhood mortality, awareness and attitudes regarding HIV/AIDS, female genital mutilation, domestic violence, and height and weight of women and children age $0-5$ from 16,688 households, and 15,683 female and 12,688 male respondents.

The EDHS survey was a cross-sectional survey, sampled nation-wide using stratified multistage cluster sampling. Each local government administrative area in the country was divided into census enumeration areas (EAs) that were used as sampling clusters to the survey. The census frame was a complete list of 84,915 EAs created for the 2007 Ethiopian Population and Housing Census (PHC). An EA was used based on a geographic area covering on average 181 households. Extra detailed information regarding the survey design and the sampling technique can be obtained from the 2016 EDHS report of [12].

A total of 645 EAs (202 in urban and 443 in rural areas) were selected with an approximately proportional to EA size (based on the 2007 PHC). The household survey dataset in SPSS formats was requested and obtained from the DHS program website [12]. The 2016 EDHS was the fourth DHS conducted in Ethiopia, following the 2000, 2005, and 2011 EDHS surveys. The EDHS data are publicly available and contain data related to maternal, infant, and child mortality with sociodemographic, economic, and health variables.

The dependent variable is children with under-five mortality, which was measured from women's questionnaire used to collect information from eligible women aged 15-49, and the asked questions were as follows: background characteristics (age, sex, education, ...), birth history and childhood mortality, family planning (including knowledge, use, and sources of contraceptive methods), fertility preferences, antenatal visit, place of delivery, and postnatal care, breastfeeding and infant feeding practices, vaccination of child and childhood illness, women's work and husband's background characteristics, and others [12]. In the current study, the dependent variable was recorded in dichotomous form as death occurred (yes) and not occurred (no). The independent variables considered were fathers' and mothers' educational status, the presence of multiple twin, region the families were lived in, place of delivery, the presence of mother and father/husband occupation, current marital status of mothers, age of mothers at first birth, source of drinking water, type of toilet facility, breastfeeding status, birth order number, religion they believe, use of the contraceptive method, vaccination of child, family size, wealth index, sex of child, mother's age group (at the survey time), number of antenatal visits at pregnancy period, and preceding birth interval. Those variables were considered due to the availability in the dataset and previous literature studies. The variables were categorized to make it easy for analysis purpose (Table 1).

Pearson chi-square $\left(X^{2}\right)$ and logistic regression were conducted for data analysis using STATA 14 software. The chi-square test of association was used to statistically test whether the significant association was existed between under-five child mortality and other independent categorical variables or not. To determine the significant factor of under-five mortality, the response variable was categorized as follows: death occurred (yes) and not occurred (no), and a binary outcome and logistic regression were employed. A $p$ value $\leq 0.05$ is used to test the presence of the significant association between the dependent and independent variables.

2.3. Ethical Considerations. The analyses were done using the publicly available data of the 2016 DHS of Ethiopia. Since the data used for analyses were secondary sources, no ethical consideration was undertaken.

\section{Results}

As described earlier, child mortality is associated with sociodemographic, economic, location, and health-related factors. In this section, therefore, we explore whether there are significant associations exist between child mortality and the independent variables listed in (Table 1).

3.1. Educational Qualification. We find a significant statistical difference between fathers' and mothers' educational qualifications with U5M (under-five mortality) $\left(X^{2}(2)=245.7, p \leq 0.001\right)$ and $\left(X^{2}(2)=421, p \leq 0.001\right)$, respectively. Here, the chi-square test value is computed as the sum of the square of the differences between the observed and expected categorical responses and divided by the expected value, between two or more independent categories; it implies that the larger the value, the larger the difference, and the smaller the value, the smaller the difference. The educational qualification of fathers and mothers chi-square values 245.7 and 421 indicated that larger difference was found between the observed and expected values of U5M. The result shows that about $62.10 \%$ of children's fathers were illiterate, of which $33.60 \%$ children were died; below one-third $(29.70 \%)$ of children's fathers were completed primary education, and only $8.20 \%$ were completed secondary school and above. From these, we expect that when the educational qualification of children's fathers increased child 
TABLE 1: Description of independent variables included in the study.

\begin{tabular}{lcc}
\hline Variables & Categorical variable description & $\begin{array}{c}\text { No of } \\
\text { categories }\end{array}$ \\
\hline Region & Tigray, Afar, Amhara, Oromia, Somali, Benishangul-Gumuz, SNNPR, Gambela, Harari, \\
Dire Dawa & 10 \\
Fathers' and mothers' education & No education, primary, secondary and above \\
level & Single, multiple \\
Twin child status & Home, public sector, private sector \\
Place of delivery & Not working, had working \\
Mothers' and fathers' occupation & Others, married \\
status & $\leq 16,>16$ \\
Mothers' current marital status & Piped, others \\
Age of mothers at first birth & No, yes \\
Sources of drinking water & Use toilet, no any kind of toilet \\
Types of toilet facility & First, 2-3, 4 and above \\
Breast feeding & Orthodox, Muslim, others \\
Birth order number & No, yes \\
Religion & No, yes \\
Contraceptive method & $1-3,4-6, \geq 7$ \\
Vaccination of child & Poor, medium, rich \\
Family size & Male, female \\
Wealth index & Below 20, 20-29, 30-39, 40 and above \\
Sex of child & No visits, 1-3, 4 and above visited \\
Mothers' age group (years) & $0-24,25-36,>36$ \\
Number of antenatal visits & 2 \\
Preceding birth interval (months) & 2 \\
\hline
\end{tabular}

mortality decreased. Regarding children's mothers, an educational level above three-fourth $(76.30 \%)$ of the total mothers was illiterate, of these more than half $(41.50 \%)$ children were died. It is below 25\%, the mothers who have attended primary, secondary, and above educational levels $(20.30 \%$ primary and $3.40 \%$ secondary and above). Combining the results indicated children born from both illiterate mothers and fathers were highly affected by child mortality, indicates that child mortality reduced when parents' educational levels increased (Table 2).

3.2. Geopolitical Regions. Table 3 indicates that a statistically significant difference was observed between Ethiopia's ten geopolitical regions (only rural settings) and the under-five child mortality $\left(X^{2}(9)=90.77, p \leq 0.001\right)$. The results indicated that children from Oromia region $(7.60 \%)$, followed by Southern Nations, Nationalities, and Peoples (SNNP) of Ethiopia (7.0\%) and then Amhara region (6.50\%), were the highest under-five mortality recorded regions, while children in the Dire Dawa city administration (rural households only) have the lowest under-five mortality (1.80\%), followed by Harari $(2.0 \%)$ and Gambela (2.70\%). We found a higher under-five survival in the Oromia region (9.0\%) and SNNP $(7.10 \%)$, which together constitute $16.10 \%$ of under-five survival. Unsurprisingly, the two regions (Oromia and SNNP) also had accompanied the higher under-five mortality, which together constitute $14.60 \%$ of under-five mortality in the country.

3.3. Twin Child. Among the total given-birth children's within the previous five years undergone the survey, only about $3.90 \%$ have been born in multiple twins, while about $96.10 \%$ were born in singleton. From the multiple twins given birth (3.90\%), about $3.0 \%$ died, indicated that the odds of dying are more than 3 times the odds of surviving. About $46 \%$ of children born in singleton have gotten the death of under-five mortality. The chi-square test of association result also indicates the presence of a significant difference between under-five mortality and twin status $\left(X^{2}(1)=196.8, p\right.$ value $\left.\leq 0.001\right)$ (Table 4$)$.

3.4. Place of Delivery. Table 5 indicates a significant association between place of delivery and under-five mortality $\left(X^{2}(2)=559.10, p\right.$ value $\left.\leq 0.001\right)$, of children from rural resident mothers. Among the total of given birth in five years before the survey, getting the death of under-five was $49.20 \%$, the highest death was recorded in home-delivered children $(45.30 \%)$, followed by the public sector $(3.50 \%)$, and the lowest was in the private sector $(0.40 \%)$. The percentage of surviving in private sector delivery is double of getting death in the same place, to the percentage of surviving in the public sector is more than three times of getting death, but getting death in-home delivery is more than those who survive.

3.5. Occupation. The chi-square test of association (Table 6) indicates that mothers' occupation $\left(X^{2} \quad(1)=67.55\right.$, $p \leq 0.001)$ and fathers' occupation $\left(X^{2}(1)=559.1, p \leq 0.001\right)$ being had a working and not working are significantly associated with under-five child mortality. About $26.80 \%$ of children from not working mothers were getting death, while $22.40 \%$ of death was from working mothers, implies that more death was occurred from not working mothers. On the other hand, about 4 deaths from 5 children $(40.50 \%)$ 
TABLe 2: Parent's education qualification on child mortality.

\begin{tabular}{llrl}
\hline $\begin{array}{l}\text { Educational } \\
\text { qualification }\end{array}$ & No & Yes & Total \\
\hline
\end{tabular}

Father's education

level

No education $\quad 3376(28.50) \quad 3985(33.60) \quad 7361(62.10)$

Primary $\quad 1967(16.60) \quad 1550(13.10) \quad 3517(29.70)$

Secondary and above $\quad 681(5.70) \quad 299(2.50) \quad 980(8.20)$

Total $\quad 6024(50.80) \quad 5834(49.20) \quad 11858(100)$

$X^{2}(2)=245.7$,

$p \leq 0.001$

Mother's education

level

No education

Primary

Secondary and above

Total

$X^{2}(2)=421.0$,

$p \leq 0.001$

TABLe 3: Geopolitical regions on child mortality.

\begin{tabular}{|c|c|c|c|}
\hline \multirow{2}{*}{ Regions } & \multicolumn{2}{|c|}{ Child death } & \multirow{2}{*}{ Total } \\
\hline & No & Yes & \\
\hline Tigray & $652(5.50)$ & $502(4.20)$ & $1154(9.70)$ \\
\hline Afar & $625(5.30)$ & $732(6.10)$ & $1357(11.40)$ \\
\hline Amhara & $598(5.00)$ & $766(6.50)$ & $1364(11.50)$ \\
\hline Oromia & $1071(9.00)$ & $895(7.60)$ & $1966(16.60)$ \\
\hline Somali & $824(6.90)$ & $711(6.00)$ & $1535(12.90)$ \\
\hline Benishangul & $576(4.90)$ & $620(5.20)$ & $1196(10.10)$ \\
\hline SNNPR & $837(7.10)$ & $836(7.00)$ & 1673 (14.10) \\
\hline Gambela & $394(3.30)$ & $316(2.70)$ & $710(6.0)$ \\
\hline Harari & $275(2.30)$ & $231(2.00)$ & $506(4.30)$ \\
\hline Dire Dawa & $172(1.50)$ & $225(1.80)$ & $397(3.30)$ \\
\hline Total & $\begin{array}{c}6024 \\
(50.80)\end{array}$ & $\begin{array}{c}5834 \\
(49.20)\end{array}$ & $11858(100)$ \\
\hline $\begin{array}{l}X^{2}(9)=90.77 \\
p \leq 0.001\end{array}$ & & & \\
\hline
\end{tabular}

TABle 4: Presence of twin child on child mortality.

\begin{tabular}{lccc}
\hline \multirow{2}{*}{ Twin status } & \multicolumn{2}{c}{ Child death } & \multirow{2}{*}{ Total } \\
& No & Yes & \\
\hline Single & $5936(50.10)$ & $5457(46.00)$ & $11393(96.10)$ \\
Multiple & $88(0.70)$ & $377(3.20)$ & $465(3.90)$ \\
Total & $6024(50.80)$ & $5834(49.20)$ & $11858(100)$ \\
$X^{2}(1)=196.8$, & & & \\
$p \leq 0.001$ & & & \\
\hline
\end{tabular}

were occurred from working fathers, while 1 out of 5 from not working fathers.

3.6. Marital Status. Table 7 shows statistically significant differences existed among married (live in a union) and not married (live in single) marital status of under-five child mortality $\left(X^{2}(1)=20.447, p \leq 0.001\right)$. Among not married mothers, under-five child mortality was higher by $1 \%$ than not getting death; on the other hand, in married mothers, child mortality was gone below by $2.6 \%$. Of the total children who have got death $(49.20 \%)$, about $45 \%$ were died, the children born from married mothers, while about $4.20 \%$ of "unmarried" (live in single) mothers. On the contrary, a multicountry analysis held in sub-Saharan Africa concluded that unmarried mother's increases in the risk of under-five mortality [15]; this study might be due to a large number of study participants were from married (live in a union) mothers.

3.7. Age of Mothers at First Birth. Mothers' age at first birth (below and above sixteen years) shows a significant difference between the presence and absence of under-five mortality $\left(X^{2}(1)=181.8, p \leq 0.001\right)$ (Table 8$)$. Nine of twenty children were born from mothers whose first birth was given sixteen and below years old. Mothers had given first birth earlier than 16 years results in $25 \%$ of the death of their children, while $19.60 \%$ were survived. On the other hand, in mothers had given first birth above 16 years old, $24.20 \%$ of children were died, while $31.20 \%$ were alive.

3.8. Sources of Drinking Water and Toilet Facility. There was no significant difference existed among the sources of drinking water $\left(X^{2}(1)=3.105, p=0.078\right)$ and toilet facility $\left(X^{2}(1)=0.519, p=0.471\right)$ with the under-five mortality (Table 9). The chi-square value indicates that the sum of the differences between the observed and the expected value is small. Regarding children who were born from households, children who have used piped (improved) sources of drinking water were more likely to survive than getting death, the same to unimproved sources of drinking water, which means more likely to survive than death. A study has undergone in Ethiopia based on the evidence of 2011 EDHS, and sources of drinking water significantly associated with under-five mortality [16].

Children born from households were users of the toilet; survival status was $0.5 \%$ exceeded with those of getting death and from those of any kind of toilet facility household children surviving status exceed by $1.10 \%$ from getting death. Generally, the presence of piped sources of drinking water and toilet facility was very less, $1.90 \%$ and $48.50 \%$, respectively. More than four children out of five were born from households, whose sources of drinking water were unimproved. A study conducted in 33 African countries about infant deaths revealed that a $1 \%$ increase in access to improved sanitation would reduce infant mortality by a rate of two infant deaths per 1000 live births [17]; in rural Zimbabwe, households with no toilet facilities are $2.43 \%$ more liable to child mortality [18], and access to improved sanitation is associated with lower mortality $(\mathrm{OR}=0.77)$ [19]. Access to safe drinking water and improved sanitation are associated with better health outcomes [7].

3.9. Breastfeeding. Breastfeeding history of children in the first two years of life shows a significant difference with under-five mortality $\left(X^{2}(1)=756.3, p \leq 0.001\right)$ (Table 10). The chi-square value indicates that the difference between the observed values and the expected values was much 
Table 5: Place of delivery on child mortality.

\begin{tabular}{lccc}
\hline Place of delivery & No & Child death & Yes \\
\hline Home & $4580(38.60)$ & $5362(45.30)$ & $9944(83.90)$ \\
Public sector & $1351(11.40)$ & $419(3.50)$ & $1770(14.90)$ \\
Private sector & $91(0.80)$ & $53(0.40)$ & $144(1.20)$ \\
Total & $6024(50.80)$ & $5834(49.20)$ & $11858(100)$ \\
$X^{2}(2)=559.1, p \leq 0.001$ & & & \\
\hline
\end{tabular}

TABLe 6: Parents' occupation on child mortality.

\begin{tabular}{lccc}
\hline Parents' occupation & No & Child death & Yes \\
\hline Mothers' occupation & & & \\
Not working & $3732(31.50)$ & $260(26.80)$ & $6912(58.30)$ \\
Had working & $2292(19.30)$ & $5834(49.20)$ & $4946(41.70)$ \\
Total & $6024(50.80)$ & & $11858(100)$ \\
$X^{2}(1)=67.551, p \leq 0.001$ & & & $1031(8.70)$ \\
Fathers' occupation & & $4803(40.50)$ & $2008(16.90)$ \\
Not working & $977(8.20)$ & $5834(49.20)$ & $9850(83.10)$ \\
Had working & $5047(42.60)$ & & $11858(100)$ \\
Total & $6024(50.80)$ & & \\
$X^{2}(1)=559.1, p \leq 0.001$ & & & \\
\hline
\end{tabular}

TABLE 7: Current mothers' marital status on child mortality.

\begin{tabular}{|c|c|c|c|}
\hline \multirow{2}{*}{ Current mothers' marital status } & \multicolumn{2}{|c|}{ Child death } & \multirow{2}{*}{ Total } \\
\hline & No & Yes & \\
\hline Others & $383(3.20)$ & $498(4.20)$ & $881(7.40)$ \\
\hline Married & $5641(47.60)$ & $5336(45.00)$ & $10977(92.60)$ \\
\hline Total & $6024(50.80)$ & $5834(49.20)$ & $11858(100)$ \\
\hline$X^{2}(1)=20.447, p \leq 0.001$ & & & \\
\hline
\end{tabular}

TABle 8: Age of mothers at first birth on child mortality.

\begin{tabular}{|c|c|c|c|}
\hline \multirow{2}{*}{$\begin{array}{l}\text { Mothers age at first } \\
\text { birth }\end{array}$} & \multicolumn{2}{|c|}{ Child death } & \multirow{2}{*}{ Total } \\
\hline & No & Yes & \\
\hline$\leq 16$ & $2319(19.60)$ & $2964(25.00)$ & $5283(44.60)$ \\
\hline$>16$ & $3705(31.20)$ & $2870(24.20)$ & $6575(55.40)$ \\
\hline $\begin{array}{l}\text { Total } \\
X^{2} \\
(1)=181,80, p<0001\end{array}$ & $6024(50.80)$ & $5834(49.20)$ & $11858(100)$ \\
\hline
\end{tabular}

bigger. Of the study participants, about $43.10 \%$ of children did not have breastfeeding history in the first two years of life. Of these, about $15.60 \%$ children with breastfeeding were alive, while $27.50 \%$ were getting death.

3.10. Mothers' Age Group and Birth Order Number. The mothers' age group and the birth-order number show a significant differences with under-five child mortality $\left(X^{2}\right.$
$(3)=2197, p \leq 0.001)$ and $\left(X^{2}(2)=131.3, p \leq 0.001\right)$; respectively (Table 11). The highest under-five mortality was observed among mothers with age group of 30-39 years (21.80\%); secondly, mothers aged 40 and above (15.90\%); and thirdly, mothers with age group 20-29 years (10.50\%). The lowest under-five mortality was recorded in below 20 years aged mothers $(1.10 \%)$. The birth order number increased with under-five mortality: first order (8.60\%); $2-3$ order (14\%); and 4 and above birth order (26.60\%). The highest, more than half, child death was from 4 and above birth orders.

3.11. Religion. Religious beliefs among the rural households showed a significant difference with under-five mortality $\left(X^{2}(2)=21.202, p \leq 0.001\right)$ (Table 12). The highest death of children was found among Muslim religious belief followers (26.60\%); it might be due to more than half $(52.70 \%)$ of the survey participants were Muslims, leads to increase the probability. Among the Orthodox belief followers (13.30\%), children were died, and only $9.30 \%$ of child death was from neither Orthodox nor Muslim belief followers. 
TABLE 9: Sources of drinking water and toilet facility on child mortality.

\begin{tabular}{lccc}
\hline & & Child death & Yes \\
\hline $\begin{array}{l}\text { Sources of drinking water } \\
\text { Piped }\end{array}$ & No & $99(0.80)$ & Total \\
Others & $129(1.10)$ & $5735(48.40)$ & $11630(98.10)$ \\
Total & $5895(49.70)$ & $5834(49.20)$ & $11858(100)$ \\
$X^{2}(1)=3.105, p=0.078$ & $6024(50.80)$ & & $2851(24.00)$ \\
\hline Type of toilet facility & & $2980(25.20)$ & $5755(48.50)$ \\
Use toilet & $2904(24.50)$ & $5834(49.20)$ & $6103(51.50)$ \\
No any kind of toilet & $3120(26.30)$ & & $11858(100)$ \\
Total & $6024(50.80)$ & & \\
$X^{2}(1)=0.519, p=0.471$ & & & \\
\hline
\end{tabular}

TABLE 10: Breastfeeding status on child mortality.

\begin{tabular}{lccc}
\hline \multirow{2}{*}{ Breastfeeding status } & \multicolumn{2}{c}{ Child death } & \multirow{2}{*}{ Total } \\
& No & Yes & \\
\hline No & $1856(15.60)$ & $3257(27.50)$ & $5113(43.10)$ \\
Yes & $4168(35.20)$ & $2577(21.70)$ & $6745(56.90)$ \\
Total & $6024(50.80)$ & $5834(49.20)$ & $11858(100)$ \\
$X^{2}(1)=$ & & & \\
$756.30, p \leq 0.001$ & & & \\
\hline
\end{tabular}

TABLE 11: Mothers' age group and birth order number on child mortality.

\begin{tabular}{lccc}
\hline & \multicolumn{2}{c}{ Child death } & \multirow{2}{*}{ Total } \\
& No & Yes & \\
\hline Mothers' age group & & & \\
Below 20 years & $713(6.00)$ & $123(1.10)$ & $836(7.10)$ \\
20-29 years & 2936 & $1250(10.50)$ & $4186(35.30)$ \\
& $(24.80)$ & & 4598 \\
$30-39$ years & $2017(17.00)$ & $2581(21.80)$ & $(38.80)$ \\
40 and above years & $358(3.00)$ & $1880(15.90)$ & $2238(18.90)$ \\
Total & 6024 & 5834 & $11858(100)$ \\
$X^{2}(3)=2197.0$, & $(50.80)$ & $(49.20)$ & \\
$p \leq 0.001$ & & & \\
Birth order number & & & \\
First & $1350(11.40)$ & $1021(8.60)$ & $2371(20.00)$ \\
$2-3$ & $2047(17.20)$ & $1659(14.00)$ & $3706(31.20)$ \\
4 and above & 2627 & $3154(26.60)$ & $5781(48.80)$ \\
& $(22.20)$ & 5834 & $11858(100)$ \\
Total & 6024 & $(49.20)$ \\
$X^{2}(2)=131.3$, & $(50.80)$ & & \\
$p \leq 0.001$ & & & \\
\hline
\end{tabular}

3.12. Contraceptive Methods and Child Vaccination on Child Mortality. A higher number of child deaths (41\%) were associated with mothers who did not practice contraception. Only 1 of 5 mothers was the user of contraceptive methods; only two of ten children were getting vaccinated in rural resident households. Nine of ten children died were from nonvaccinated children. The contraceptive used mothers $\left(X^{2}(1)=64.7, p \leq 0.001\right)$ and vaccinated children $\left(X^{2}(1)=\right.$ 644.3, $p \leq 0.001$ ) show a significant difference with underfive mortality (Table 13).

3.13. Family Size and Wealth Index on Child Mortality. The highest child mortality (23.60\%) was from a family size of 4-6 family size per household of the total $49.10 \%$ study participants in rural Ethiopia. In a family size of above six, $40.50 \%, 21 \%$ of children were getting death. Of poor economic status study participants' children (64.20\%), half of them $(32 \%)$ were getting death. The death of children concerning the variable family size $\left(X^{2} \quad(2)=27.2\right.$, $p \leq 0.001)$ shows a significant difference, while wealth index status $\left(X^{2}(2)=4.8, p=0.091\right)$ does not show a significant statistical association (Table 14).

3.14. Sex of Child. About 53.10\% of male and $46.90 \%$ of female children were considered for the survey. Of these, more male children (27\%) and less female children $(22.20 \%)$ were died compared to not getting death respective percentage values. The chi-square value $\left(X^{2}(1)=13, p \leq 0.001\right)$ indicates a significant association of sex of a child with under-five mortality in rural settings (Table 15).

3.15. Number of Antenatal Visits and Preceding Birth Interval. Of the total study participant mothers, about $72 \%$ were not yet found antenatal visits; of these, $42 \%$ of children died. When the number of mothers' antenatal visits increased, the result shows in the reduction of under-five mortality. About half $(49.10 \%)$ children were born with the preceding birth interval of fewer than 2 years, and $27.20 \%$ died. As the percentage value indicates the preceding birth interval increases, the under-five mortality reversed in rural born children. Both antenatal visits and preceding birth interval indicate a significant association of under-five child mortality $\left(X^{2}(2)=1041, p \leq 0.001\right)$ and $\left(X^{2}(2)=242, p \leq 0.001\right)$, respectively (Table 16 ).

3.16. Determinant Factors of Under-Five Mortality: Multivariable Analysis. The multivariable analyses to investigate the determinants of under-five mortality in rural Ethiopia 
TABLE 12: Religious beliefs on child mortality.

\begin{tabular}{|c|c|c|c|}
\hline \multirow{2}{*}{ Religion } & \multicolumn{2}{|c|}{ Child death } & \multirow{2}{*}{ Total } \\
\hline & No & Yes & \\
\hline Orthodox & $1595(13.40)$ & $1577(13.30)$ & $3172(26.70)$ \\
\hline Muslim & $3090(26.10)$ & $3157(26.60)$ & $6247(52.70)$ \\
\hline Others & $1339(11.30)$ & $1100(9.30)$ & $2439(20.60)$ \\
\hline Total & $6024(50.80)$ & $5834(49.20)$ & $11858(100)$ \\
\hline$X^{2}(2)=21.202, p \leq 0.001$ & & & \\
\hline
\end{tabular}

TABLE 13: Use of contraceptive methods and child vaccination on child mortality.

\begin{tabular}{|c|c|c|c|}
\hline & \multicolumn{2}{|c|}{ Child death } & \multirow{2}{*}{ Total } \\
\hline & No & Yes & \\
\hline \multicolumn{4}{|l|}{$\begin{array}{l}\text { Use of contraceptive } \\
\text { methods }\end{array}$} \\
\hline No & $\begin{array}{c}4662 \\
(39.30)\end{array}$ & $\begin{array}{c}4858 \\
(41.00)\end{array}$ & $\begin{array}{c}9520 \\
(80.30)\end{array}$ \\
\hline Yes & $\begin{array}{c}1362 \\
(11.50)\end{array}$ & $976(8.20)$ & $\begin{array}{c}2338 \\
(19.70)\end{array}$ \\
\hline Total & $\begin{array}{c}6024 \\
(50.80)\end{array}$ & $\begin{array}{c}5834 \\
(49.20)\end{array}$ & $\begin{array}{c}11858 \\
(100)\end{array}$ \\
\hline \multicolumn{4}{|l|}{$X^{2}(1)=64.736, p \leq 0.001$} \\
\hline \multicolumn{4}{|l|}{ Vaccination of child } \\
\hline No & $\begin{array}{c}4365 \\
(36.80)\end{array}$ & $\begin{array}{c}5286 \\
(44.60)\end{array}$ & $\begin{array}{c}9651 \\
(81.40)\end{array}$ \\
\hline Yes & $\begin{array}{c}1659 \\
(14.00)\end{array}$ & $548(4.60)$ & $\begin{array}{c}2207 \\
(18.60)\end{array}$ \\
\hline Total & $\begin{array}{c}6024 \\
(50.80)\end{array}$ & $\begin{array}{c}5834 \\
(49.20)\end{array}$ & $\begin{array}{l}11858 \\
(100)\end{array}$ \\
\hline$X^{2}(1)=644.3, p \leq 0.001$ & & & \\
\hline
\end{tabular}

Table 14: Family size and wealth index on child mortality.

\begin{tabular}{lccc}
\hline & \multicolumn{2}{c}{ Child death } & \multirow{2}{*}{ Total } \\
& No & Yes & \\
\hline Family size & $690(5.80)$ & $546(4.60)$ & $1236(10.40)$ \\
$1-3$ & $3018(25.50)$ & 2806 & $5824(49.10)$ \\
$4-6$ & & $(23.60)$ & 4798 \\
& & & \\
7 and above visited & $2316(19.50)$ & $2482(21.00)$ & $(40.50)$ \\
& 6024 & 5834 & $11858(100)$ \\
Total & $(50.80)$ & $(49.20)$ & \\
$X^{2}(2)=$ & & & \\
$27.20, p \leq 0.001$ & & 3799 & $7615(64.20)$ \\
Wealth index status & $3816(32.20)$ & $(32.00)$ & \\
Poor & $1036(8.80)$ & $928(7.80)$ & $1964(16.60)$ \\
Medium & $1172(9.80)$ & $1107(9.40)$ & $2279(19.20)$ \\
Rich & 6024 & 5834 & $11858(100)$ \\
Total & $(50.80)$ & $(49.20)$ & \\
$X^{2}(2)=$ & & & \\
$4.788, p=0.091$ & &
\end{tabular}

were performed using the binary logistic regression model (Table 17). Due to the presence of many factors included in the study, we cannot check the interaction terms of the factors. This may be the limitation in this multivariable analysis. Individual variables were included in the multivariable regression model if it was significant at $p \leq 0.2$ in univariable analysis or based on biological plausibility.

The result of the multivariable analyses revealed that the factors such as regions: Amhara $(\mathrm{AOR}=1.32 ; 95 \% \mathrm{CI}$ : 1.08-1.62), SNNPR (AOR $=1.43 ; 95 \% \mathrm{CI}: 1.13-1.81)$, and Dire Dawa (AOR $=1.78$; 95\% CI: 1.28-2.47) show significant effect of under-five mortality in rural born children compared to Tigray region.

Father's educational level of secondary school and above completed $(\mathrm{AOR}=0.77 ; 95 \% \mathrm{CI}: 0.63-0.94)$, and mother's educational level of primary school completed $(\mathrm{AOR}=0.82$; 95\% CI: 0.72-0.93); multiple twin child ( $\mathrm{AOR}=4.50$; 95\% CI: 3.38-5.98); public sector delivery $(\mathrm{AOR}=0.65$; 95\% CI: $0.55-0.76)$; occupation of mothers $(\mathrm{AOR}=1.28$; 95\% CI:1.16-1.42 of had working) and of fathers ( $\mathrm{AOR}=1.45 ; 95 \% \mathrm{CI}: 1.25-1.69$ of had working); age at first birth of mothers $(\mathrm{AOR}=0.41 ; 95 \% \mathrm{CI}$ : $0.37-0.45)$ of aged above 16; current breastfeeding status $(\mathrm{AOR}=0.60 ; 95 \% \mathrm{CI}$ : $0.55-0.66)$ of yes; birth order $(\mathrm{AOR}=1.18$; 95\% CI: 1.02-1.37) of order 2-3; religious belief of Muslim (AOR $=1.20 ; 95 \% \mathrm{CI}: 1.02-1.41)$; users of contraceptive method $(\mathrm{AOR}=0.80 ; 95 \% \mathrm{CI}$ : 0.71-0.90); vaccinated child $(\mathrm{AOR}=0.52 ; \quad 95 \% \mathrm{CI}: \quad 0.46-0.60) ;$ and family size $((\mathrm{AOR}=0.74 ; \quad 95 \% \mathrm{CI}: \quad 0.63-0.86$ of size $4-6)$ and ( $\mathrm{AOR}=0.44 ; 95 \% \mathrm{CI}: 0.36-0.52$ of size seven and above) $)$ are significant factors of under-five mortality.

Regarding mother's age group, $((\mathrm{AOR}=3.88 ; 95 \% \mathrm{CI}$ : $3.08-4.90)$ of mothers aged $20-29,(\mathrm{AOR}=16.29$; $95 \% \mathrm{CI}$ : 12.66-20.96) of mothers aged 30-39, and $(\mathrm{AOR}=55.97$; 95\% CI: 42.27-74.13) of mothers aged 40 and above); number of antenatal visits $(\mathrm{AOR}=0.50 ; 95 \% \mathrm{CI}$ : $0.43-0.58$ for $1-3$ visits and $\mathrm{AOR}=0.46$; 95\% CI: $0.39-0.54$ for four and above visits); and preceding birth interval of 25-36 months $(\mathrm{AOR}=0.55 ; 95 \% \mathrm{CI}$ : $0.48-0.62)$ and above 36 months $(\mathrm{AOR}=0.30 ; 95 \% \mathrm{CI}: 0.26-0.34)$ are significant determinant factors of under-five mortality in rural settings (Table 17).

\section{Discussion}

In this study, the covariates, namely, mother's and father's educational level, regions, twin child, place of delivery, occupation of mothers and fathers, marital status, age of mother at first birth, breastfeeding status, mother's age 
TABLE 15: Sex of child on child mortality.

\begin{tabular}{lccc}
\hline \multirow{2}{*}{ Sex of child } & \multicolumn{2}{c}{ Child death } & \multirow{2}{*}{ Total } \\
& No & Yes & \\
\hline \multirow{2}{*}{ Male } & 3099 & 3194 & 6293 \\
& $(26.10)$ & $(27.00)$ & $(53.10)$ \\
Female & 2925 & 2640 & 5565 \\
& $(24.70)$ & $(22.20)$ & $(46.90)$ \\
Total & 6024 & 5834 & $11858(100)$ \\
$X^{2}(1)=12.989$, & $(50.80)$ & $(49.20)$ & \\
$p \leq 0.001$ & & & \\
\hline
\end{tabular}

TABLE 16: Number of antenatal visits and preceding birth interval on child mortality.

\begin{tabular}{|c|c|c|c|}
\hline & \multicolumn{2}{|c|}{ Child death } & \multirow{2}{*}{ Total } \\
\hline & No & Yes & \\
\hline \multicolumn{4}{|l|}{$\begin{array}{l}\text { Number of antenatal } \\
\text { visits }\end{array}$} \\
\hline No visits & $\begin{array}{c}3551 \\
(30.00)\end{array}$ & $\begin{array}{c}4990 \\
(42.00)\end{array}$ & $\begin{array}{c}8541 \\
(72.00)\end{array}$ \\
\hline $1-3$ & $\begin{array}{c}1260 \\
(10.60)\end{array}$ & $454(3.90)$ & $\begin{array}{c}1714 \\
(14.50)\end{array}$ \\
\hline 4 and above visited & $\begin{array}{c}1213 \\
(10.20)\end{array}$ & $390(3.30)$ & $\begin{array}{c}1603 \\
(13.50)\end{array}$ \\
\hline Total & $\begin{array}{c}6024 \\
(50.80)\end{array}$ & $\begin{array}{c}5834 \\
(49.20)\end{array}$ & $11858(100)$ \\
\hline \multicolumn{4}{|l|}{$\begin{array}{l}X^{2}(2)=1041.0 \\
p \leq 0.001\end{array}$} \\
\hline \multicolumn{4}{|l|}{ Preceding birth interval } \\
\hline $0-24$ months & $\begin{array}{c}2599 \\
(21.90)\end{array}$ & $\begin{array}{c}3222 \\
(27.20)\end{array}$ & $\begin{array}{c}5821 \\
(49.10)\end{array}$ \\
\hline 25-36 months & $\begin{array}{c}1543 \\
(13.00)\end{array}$ & $\begin{array}{c}1461 \\
(12.30)\end{array}$ & $\begin{array}{c}3004 \\
(25.30)\end{array}$ \\
\hline Above 36 months & $\begin{array}{c}1882 \\
(15.90)\end{array}$ & $1151(9.70)$ & $\begin{array}{c}3033 \\
(25.60)\end{array}$ \\
\hline Total & $\begin{array}{c}6024 \\
(50.80)\end{array}$ & $\begin{array}{c}5834 \\
(49.20)\end{array}$ & $11858(100)$ \\
\hline $\begin{array}{l}X^{2}(2)=242.10 \\
p \leq 0.001\end{array}$ & & & \\
\hline
\end{tabular}

group, birth order number, religious belief, use of contraceptive method, child vaccination, family size, sex of child, number of antenatal visits, and preceding birth interval were significantly associated with under-five mortality in univariable analysis, while in multivariable analyses, the covariates such as father's educational level (secondary school and above completed), mother's educational level (primary school completed), being born in multiple twin, public sector delivery, the presence of occupation of mothers and fathers, mother's age at first birth, breastfeeding, birth order (2-3), religious belief (Muslim), use of contraceptive method, vaccinated child, family size, mother's age group, number of antenatal visits, and preceding birth interval had significantly affected the survival of under-five children in rural settings.

Even if evidence shows that in Ethiopia, a gradual decrease of under-five mortality is observed, it is still high in the rural settings of the country $[8,9,11,12]$. Researchers have identified multiple risk factors for child mortality based on the characteristics of mothers, fathers, and children and the different circumstances of birth. The stratification of some findings from previous studies was limited as most studies in Ethiopia restricted their analyses to the whole death of under-five in the country, but the level of risk factors was different among rural and urban population, especially in the presence of poor infrastructure, low-economic group, and limited information flow in rural settings made the level of risk factors is estimated to be high.

Based on the current study, the regional differences are observed in the survival of under-five children. It was found that the Amhara region 32\% (8\%-62\%), SNNPR 43\% $(13 \%-81 \%)$, and Dire Dawa $78 \%(28 \%-147 \%)$ were more likely to die compared to Tigray region (as a baseline randomly selected reference), for the rural settings, by considering the other variables constant. This is supported by the evidence of the four EDHS surveys conducted in the country, in which differentials in child mortality by region are pronounced; lower in Addis Ababa (urban setting) and higher in a heterogeneity population (urban and rural settings) $[8,9,11,12]$. The study conducted on the trend of under-five mortality prevailed that significant differences still exist across the administrative regions of the country [10].

Regarding the educational level of parents, fathers had attended secondary school and above was 23\% (6\%-37\%) lower in under-five mortality compared to illiterate, and also mothers had attended primary school education was $18 \%(7 \%-28 \%)$ less likely to die than those who had not attended education. It is expected that the educational qualification of parents increases; it would increase the survival status of children. As evidence shown in prior studies, the high mothers' education level has resulted in increasing the maternal awareness about infant health and hygiene facilities, hereby resulted in the decline of under-five mortality rates in sub-Saharan African countries [20], Malawi and Uganda [21], Madagascar [22], Tanzania [23], and Nigeria [24]. Based on a systematic review and metaanalysis, a study was undergone in Ethiopia on the effects of maternal education on infant mortality which indicated that infants born from mothers who had attended primary education was associated with a $28 \%$ reduction in the odds of infant mortality compared to those infants born from mothers who were illiterate [25]; in the current study, it shows $18 \%$ reduction. Education plays a great role in increasing healthcare awareness, and it helps the parents and the community at large to remove cultural barriers and keep the health of the household to reduce child mortality. Improvements in access to education have helped to narrow the gender gap and have benefited the poorest households. The EDHS surveys conducted in the country-wide indicated that mothers' education was inversely related to the child's risk of dying $[8,9,11]$. As a result, we can conclude that educating mothers is a beneficial effect on reducing childhood mortality rates.

Working mothers had 28\% (16\%-42\%) and fathers had $45 \%$ (25\%-69\%) more likely to child death than not working parents. However, it is expected that had working parents 
TABLE 17: Binary logistic analysis of under-five mortality (multivariable analyses): rural Ethiopia.

\begin{tabular}{|c|c|c|c|c|}
\hline Variables & Category & AOR (95\% CI: AOR) & Robust std. error & $p$ value \\
\hline \multirow{10}{*}{ Region } & Tigray & Ref & - & - \\
\hline & Afar & $1.08(0.83,1.40)$ & 0.14 & 0.559 \\
\hline & Amhara & $1.32(1.08,1.62)$ & 0.14 & $0.007^{*}$ \\
\hline & Oromia & $0.94(0.75,1.17)$ & 0.11 & 0.575 \\
\hline & Somali & $0.78(0.61,1.01)$ & 0.10 & 0.062 \\
\hline & Benishangul-Gumuz & $1.09(0.86,1.39)$ & 0.13 & 0.454 \\
\hline & SNNPR & $1.43(1.13,1.81)$ & 0.17 & $0.003^{*}$ \\
\hline & Gambela & $1.13(0.85,1.50)$ & 0.16 & 0.388 \\
\hline & Harari & $1.06(0.78,1.43)$ & 0.16 & 0.722 \\
\hline & Dire Dawa & $1.78(1.28,2.47)$ & 0.30 & $0.001^{*}$ \\
\hline \multirow{3}{*}{ Father's education level } & No education & Ref & - & - \\
\hline & Primary completed & $1.03(0.93,1.15)$ & 0.06 & 0.551 \\
\hline & Secondary and above completed & $0.77(0.63,0.94)$ & 0.65 & $0.010^{*}$ \\
\hline \multirow{3}{*}{ Mother's education level } & No education & Ref & - & - \\
\hline & Primary completed & $0.82(0.72,0.93)$ & 0.05 & $0.001^{*}$ \\
\hline & Secondary and above completed & $1.21(0.89,1.63)$ & 0.19 & 0.220 \\
\hline \multirow{2}{*}{ Twin child type } & Single & Ref & - & - \\
\hline & Multiple & $4.50(3.38,5.98)$ & 0.65 & $0.001^{*}$ \\
\hline \multirow{3}{*}{ Place of delivery } & Home & Ref & - & - \\
\hline & Public sector & $0.65(0.55,0.76)$ & 0.05 & $0.001^{*}$ \\
\hline & Private sector & $1.10(0.73,1.65)$ & 0.23 & 0.663 \\
\hline \multirow{2}{*}{ Mother's occupation } & No working & Ref & - & - \\
\hline & Had working & $1.28(1.16,1.42)$ & 0.07 & $0.001^{*}$ \\
\hline \multirow{2}{*}{ Father's occupation } & No working & Ref & - & - \\
\hline & Had working & $1.45(1.25,1.69)$ & 0.11 & $0.001^{*}$ \\
\hline \multirow{2}{*}{ Marital status } & Others & Ref & - & - \\
\hline & Married & $0.95(0.76,1.17)$ & 0.10 & 0.617 \\
\hline \multirow{2}{*}{ Age at first birth (mother's) } & $\leq 16$ & Ref & - & - \\
\hline & $>16$ & $0.41(0.37,0.45)$ & 0.02 & $0.001^{*}$ \\
\hline \multirow{2}{*}{ Breastfeeding status } & No & Ref & - & - \\
\hline & Yes & $0.60(0.55,0.66)$ & 0.03 & $0.001^{*}$ \\
\hline \multirow{3}{*}{ Birth order number } & First & Ref & - & - \\
\hline & $2-3$ & $1.18(1.02,1.37)$ & 0.09 & $0.022^{*}$ \\
\hline & 4 and above & $1.06(0.91,1.24)$ & 0.08 & 0.418 \\
\hline \multirow{3}{*}{ Religious belief } & Orthodox & Ref & - & - \\
\hline & Muslim & $1.20(1.02,1.41)$ & 0.10 & $0.026^{*}$ \\
\hline & Others & $0.85(0.71,1.02)$ & 0.08 & 0.080 \\
\hline \multirow{2}{*}{ Contraceptive used } & No & Ref & - & - \\
\hline & Yes & $0.80(0.71,0.90)$ & 0.05 & $0.001^{*}$ \\
\hline \multirow{2}{*}{ Vaccination of child } & No & Ref & - & - \\
\hline & Yes & $0.52(0.46,0.60)$ & 0.03 & $0.001^{*}$ \\
\hline \multirow{3}{*}{ Family size } & $1-3$ & Ref & - & - \\
\hline & $4-6$ & $0.74(0.63,0.86)$ & 0.06 & $0.001^{*}$ \\
\hline & 7 and above & $0.44(0.36,0.52)$ & 0.04 & $0.001^{*}$ \\
\hline \multirow{2}{*}{ Sex of child } & Male & Ref & - & - \\
\hline & Female & $0.92(0.84,1.01)$ & 0.04 & 0.071 \\
\hline \multirow{4}{*}{ Mother's age group } & Below 20 years & Ref & - & - \\
\hline & $20-29$ years & $3.88(3.08,4.90)$ & 0.46 & $0.001^{*}$ \\
\hline & $30-39$ years & $16.29(12.66,20.96)$ & 2.09 & $0.001^{*}$ \\
\hline & $40+$ years & $55.97(42.27,74.13)$ & 8.02 & $0.001^{*}$ \\
\hline \multirow{3}{*}{ Number of antenatal visits } & No visits & Ref & - & - \\
\hline & $1-3$ & $0.50(0.43,0.58)$ & 0.04 & $0.001^{*}$ \\
\hline & 4 and above visited & $0.46(0.39,0.54)$ & 0.04 & $0.001^{*}$ \\
\hline & $0-24$ months & Ref & - & - \\
\hline Preceding birth interval & 25-36 months & $0.55(0.48,0.62)$ & 0.03 & $0.001^{*}$ \\
\hline & $>36$ months & $0.30(0.26,0.34)$ & 0.02 & $0.001^{*}$ \\
\hline
\end{tabular}

NB: “*” statistically significant variables at $5 \%$ level of significance; AOR: adjusted odds ratio; CI: confidence interval; Ref: reference (the reference category was selected based on the first category as the reference of the others without any rational consideration). 
generate extra income for the improvement of their life; evidence also showed the occupation of the mother was a significant predictor of under-five mortality in Ethiopia [26]. Public sector delivery had 35\% (24\%-45\%) lowered the risk of under-five mortality compared to home delivery, while children being born in multiple twins had 4.5 times ( $\mathrm{AOR}=4.5 ; 95 \% \mathrm{CI}: 3.38-5.98)$ more to the risk of dying than born in singleton. Encouragement is needed for pregnant women to deliver at health facilities and should be done by intensifying education on where to deliver [27], and also improvement is needed on the skills and quality of health professionals to the benefit of maternal and newborn survival $[28,29]$. Twin births are uncontrollable. It is mostly a natural phenomenon, on the premise that the occurrence of twins is quasirandom [30]. A population-based study undergone in Nigeria [24] states that children born in multiple births were more than double $(\mathrm{HR}=2.19)$ as likely to die during the infancy period than infants born in singleton, in which it concludes that multiple births are strongly negatively associated with children survival. In sub-Saharan Africa, one-fifth twins die before their fifth birthday, three times the mortality rate among singletons, currently, $10.7 \%$ of under-five mortality and $15.1 \%$ of neonatal mortality in the region are due to twins [31], and also, in Ghana, the risk of mortality was higher among mothers who had multiple births compared with those of mothers who had single births [32].

As the result indicated, the age of mothers at first birth older than 16 years had been lowered the risk of dying of under-five children by $59 \%(55 \%-63 \%)$ compared to younger than 16 years old mothers. Currently, breastfeeding mothers had been $40 \%(34 \%-45 \%)$ less likely of dying of children than nonbreastfeeding children, while children of 2-3 birth order had 1.18 times $(\mathrm{AOR}=1.18$; 95\% CI: 1.02-1.37) more likely to risk of dying than first birth order. It is suggested that delaying motherhood as long as possible results in better health and survival of mothers [33]; it also increases the probability of survival of their child. Prior studies indicated that a $10 \%$ increase in exclusive breastfeeding is associated with a reduction of 5 child deaths per 1000 live births in low- and middle-income countries [34]; early initiation of breastfeeding within the first 28 days of birth the risk of neonatal deaths reduced to $15 \%$ in India [35]; children with breastfeeding were $25.5 \%$ less likely to have died before their fifth birthday in Ethiopia [16], and optimal breastfeeding practices during infancy and early childhood are important based on the result found through a systematic review and meta-analysis [36]. Regarding mother's age group, mothers aged above 20 years had more likely to death than below 20 years old mothers, while prior evidence shows that maternal age and child mortality look like a U-shaped curve, being relatively higher in among children born to mothers under age 20 and over age 40 than among mothers in the middle age groups $[8,9,11,12]$. In support of this, mothers aged $<20$ years and having a first birth were significantly associated with under-five mortality [37]. Having a religious belief of Muslims is 1.20 times (AOR $=1.20 ; 95 \% \mathrm{CI}: 1.02-1.41)$ more likely to child death than orthodox religious believers. Further analysis will be needed in the scenario of religious differentials of child mortality.

Another important finding of this study is the current use of contraceptive methods, and vaccination of a child significantly reduces the risk of death of a child, $20 \%$ $(10 \%-29 \%)$ and $48 \%(40 \%-54 \%)$, respectively. These may have similar reasons in rural settings with those of child spacing and maternal education, but in addition, the accessibility and knowledge of those facilities are limited and this is a challenge for parents. Integrated family planning through contraceptive methods and immunization through vaccination provide a higher impact on the achievement of child health goals.

We found that a higher number of family sizes, a higher number of antenatal visits, and a higher number of the preceding birth intervals had been reduced the risk of dying of children. Similar to the current study, the preceding birth interval of fewer than 2 years has higher childhood mortality rates than higher birth interval, due to that the proper spacing of births allows more time for childcare to make more maternal resources available for the care of the child and mother [38]. In this study, sex of a child was not shown significant differentials among child mortalities, while evidence shows that, on average, boys are expected to have a higher probability of dying before reaching age 5 than girls $[4,8,9,11,12,39]$.

To summarize, the result of a similar study conducted in Ethiopia indicated that sex of the child, family size, educational level of the mother, age at first birth of the mother, breastfeeding and the use of contraceptive method, and regions of children were found to be determinant of underfive child mortality [39]. Reducing child mortality rates requires multiple intervention strategies, such as access to safe drinking water, improvement in education opportunities, family planning, and tackling HIV/AIDS [40]. It is also expected that if the quality of life of the parents is improved in all aspects such as education, health service facility, and sources of income, the survival of children would be improved; it is taken into consideration that rural settings are very challenging.

\section{Conclusions}

This study has demonstrated the associated risk factors of under-five mortality in rural settings of Ethiopia. Differences in regions, educational attainment, born in twin, place of delivery, availability of occupation of parents, age of mothers at first birth, breastfeeding status, birth order, religious belief, use of a contraceptive method, child vaccination, and family size play a significant role regarding the survival of under-five children. These, among other differences, should be addressed decisively as part of any upcoming strategic interventions to improve the survival of children in line with the 2030 Sustainable Development Goals (SDGs): effective health facilities, improving the awareness of mothers about contraceptive methods and vaccination of the child for family planning and better child health strategies across all rural settings of the country, thereby equitably expanding health benefits as outlined in the SDGs, Goal 3 focusing on 
health (ensure healthy lives and promote well-being for all at all ages) of the country [41].

\section{Abbreviations}

$\begin{array}{ll}\text { ANC: } & \text { Antenatal care } \\ \text { AOR: } & \text { Adjusted odds ratio } \\ \text { CI: } & \text { Confidence interval } \\ \text { CSA: } & \text { Central Statistical Agency } \\ \text { EA: } & \text { Enumeration areas } \\ \text { EDHS: } & \text { Ethiopian Demographic and Health Survey } \\ \text { HIV/ } & \text { Human immune virus/acquired immune } \\ \text { AIDS: } & \text { deficiency syndrome } \\ \text { MDG: } & \text { Millennium Development Goal } \\ \text { PHC: } & \text { Population and Housing Census } \\ \text { SDG: } & \text { Sustainable Development Goal } \\ \text { SNNPR: } & \text { Southern Nations, Nationalities, and Peoples' } \\ & \text { Region. }\end{array}$

\section{Data Availability}

Data for this study were sourced from Demographic and Health Surveys (DHSs) and are available at http://www. dhsprogram.com/data/available-datasets.cfm.

\section{Conflicts of Interest}

The authors declare that there are no conflicts of interest.

\section{Authors' Contributions}

SG conducted a literature search, planned the study, carried out data extraction, performed data analysis and interpretation, and drafted the manuscript. SM carried out data extraction. Both authors read and approved the final manuscript.

\section{Acknowledgments}

The authors thank the MEASURE DHS Project for their support and for free access to the original data.

\section{References}

[1] UNICEF, Progress for Every Child in the SDG Era, UNICEF, New York, NY, USA, 2018.

[2] Save the Children, Global Childhood Report, Save the Children, Addis Ababa, Ethiopia, 2019.

[3] WHO, Global Health Observatory (GHO) Data, WHO, Geneva, Switzerland, 2019.

[4] United Nations Inter-Agency Group for Child Mortality Estimation (UNIGME), Levels and Trends in Child Mortality: Report 2019, Estimates Developed by the United Nations InterAgency Group for Child Mortality Estimation, United Nations Children's Fund, New York, NY, USA, 2019.

[5] United Nations Inter-Agency Group for Child Mortality Estimation (UNIGME), Levels and Trends in Child Mortality: Report 2018, Estimates Developed by the United Nations InterAgency Group for Child Mortality Estimation, United Nations Children's Fund, New York, NY, USA, 2018.
[6] "Ethiopia demographic and health survey 2011 via the DHS program STAT compiler," 2011, http://www.statcompiler. com.

[7] Ministry of Health Ethiopia, PMNCH, WHO, and World Bank, AHPSR and Participants in the Ethiopia Multi-Stake Holder Policy Review (2015). Success Factors for Women's and Children's Health, Ministry of Health Ethiopia, Addis Ababa, Ethiopia, 2015.

[8] Central Statistical Agency (Ethiopia) and ORC Macro, Ethiopia Demographic and Health Survey 2005, Central Statistical Agency and ORC Macro, Addis Ababa, Ethiopia, 2006.

[9] Central Statistical Agency (Ethiopia) and ICF International, Ethiopia Demographic and Health Survey 2011, Central Statistical Agency and ICF International, Addis Ababa, Ethiopia, 2012.

[10] E. Gurmu and J. Akim Mturi, "Trends and determinants of under-five mortality in Ethiopia: could the MDG four be met?" Southern African Journal of Demography, vol. 15, no. 1, pp. 49-80, 2014.

[11] Central Statistical Authority (Ethiopia) and ORC Macro, Ethiopia Demographic and Health Survey 2000, Central Statistical Authority and ORC Macro, Addis Ababa, Ethiopia, 2001.

[12] Central Statistical Agency (CSA) (Ethiopia) and ICF, Ethiopia Demographic and Health Survey 2016, CSA and ICF, Addis Ababa, Ethiopia, 2016.

[13] "Ethiopian people 2019. CIA world factbook," 2019, https:// theodora.com/wfbcurrent/ethiopia/ethiopia.people.html.

[14] Worldatlas, Geography Statistics of Ethiopia, Worldatlas, Addis Ababa, Ethiopia, 2017.

[15] S. Yaya, G. Bishwajit, F. Okonofua, and O. A. Uthman, "Under five mortality patterns and associated maternal risk factors in sub-Saharan Africa: a multi-country analysis," PLoS One, vol. 13, no. 10, Article ID e0205977, 2018.

[16] S. Gebretsadik and E. Gabreyohannes, "Determinants of under-five mortality in high mortality regions of Ethiopia: an analysis of the 2011 Ethiopia demographic and health survey data," International Journal of Population Research, vol. 2016, Article ID 1602761, 7 pages, 2016.

[17] A. M. Alemu, "To what extent does access to improved sanitation explain the observed differences in infant mortality in Africa?" African Journal of Primary Health Care \& Family Medicine, vol. 9, no. 1, pp. e1-e9, 2017.

[18] M. Makate and C. Makate, Is Poor Sanitation Killing More Children in Rural Zimbabwe? Results of Propensity Score Matching Method, University Library of Munich, Munich, Germany, 2016.

[19] G. Fink, I. Günther, and K. Hill, "The effect of water and sanitation on child health: evidence from the demographic and health surveys 1986-2007," International Journal of Epidemiology, vol. 40, no. 5, pp. 1196-1204, 2011.

[20] A. R. Bado and A. Sathiya Susuman, "Women's education and health inequalities in under-five mortality in selected subSaharan African countries, 1990-2015," PLoS One, vol. 11, no. 7, Article ID e0159186, 2016.

[21] L. Andriano and C. W. S. Monden, "The causal effect of maternal education on child mortality: evidence from a quasiexperiment in Malawi and Uganda," Demography, vol. 56, no. 5, p. 1765, 2019.

[22] S. Badji, Mother's Education and Increased Child Survival in Madagascar: What Can We Say?, Groupe d'Analyse et de Théorie Economique, Écully, France, 2016.

[23] C. Nattey, H. Masanja, and K. Klipstein-Grobusch, "Relationship between household socio-economic status and 
under-five mortality in Rufiji DSS, Tanzania," Global Health Action, vol. 6, no. 1, p. 19278, 2013.

[24] O. A. Uthman, M. B. Uthman, and I. Yahaya, "A populationbased study of effect of multiple birth on infant mortality in Nigeria," BMC Pregnancy and Childbirth, vol. 8, no. 1, p. 41, 2008.

[25] G. T. Kiross, C. Chojenta, D. Barker, T. Y. Tiruye, and D. Loxton, "The effect of maternal education on infant mortality in Ethiopia: a systematic review and meta-analysis," PLoS One, vol. 14, no. 7, Article ID e0220076, 2019.

[26] B. T. Woldeamanuel, "Socioeconomic, demographic, and environmental determinants of under-5 mortality in Ethiopia: evidence from Ethiopian demographic and health survey, 2016," Child Development Research, vol. 2019, Article ID 1073782, 15 pages, 2019.

[27] J. Ajaari, H. Masanja, R. Weiner, S. A. Abokyi, and S. OwusuAgyei, "Impact of place of delivery on neonatal mortality in rural Tanzania," International Journal of MCH and AIDS (IJMA), vol. 1, no. 1, pp. 49-59, 2012.

[28] C. R. Titaley, M. J. Dibley, and C. L. Roberts, "Type of delivery attendant, place of delivery and risk of early neonatal mortality: analyses of the 1994-2007 Indonesia demographic and health surveys," Health Policy and Planning, vol. 27, no. 5, pp. 405-416, 2012.

[29] UNICEF, Joint UNICEF/WHO Database 2019 of Skilled Health Personnel, Based on Population Based National Household Survey Data and Routine Health Systems, UNICEF, New York, NY, USA, 2019.

[30] S. Bhalotra and D. Clarke, "Twin birth and maternal condition," Review of Economics and Statistics, vol. 101, no. 5, 2018.

[31] C. W. S. Monden and J. Smits, "Mortality among twins and singletons in sub-Saharan Africa between 1995 and 2014: a pooled analysis of data from 90 demographic and health surveys in 30 countries," The Lancet Global Health, vol. 5, pp. 673-679, 2017.

[32] D. Dwomoh, S. Amuasi, K. Agyabeng, G. Incoom, Y. Alhassan, and A. E. Yawson, "Understanding the determinants of infant and under-five mortality rates: a multivariate decomposition analysis of demographic and health surveys in Ghana, 2003, 2008 and 2014," BMJ Global Health, vol. 4, no. 4, Article ID e001658, 2019.

[33] J. Mirowsky, “Age at first birth, health, and mortality," Journal of Health and Social Behavior, vol. 46, no. 1, pp. 32-50, 2005.

[34] R. Azuine, J. Murray, N. Alsafi, and G. K. Singh, "Exclusive breastfeeding and under-five mortality, 2006-2014: a crossnational analysis of 57 low- and-middle income countries," International Journal of MCH and AIDS (IJMA), vol. 4, no. 1, pp. 13-21, 2015.

[35] D. Phukan, M. Ranjan, and L. K. Dwivedi, "Impact of timing of breastfeeding initiation on neonatal mortality in India," International Breastfeeding Journal, vol. 13, no. 1, p. 27, 2018.

[36] M. J. Sankar, B. Sinha, R. Chowdhury et al., "Optimal breastfeeding practices and infant and child mortality: a systematic review and meta-analysis," Acta Paediatrica, vol. 104, pp. 3-13, 2015.

[37] P. Ghimire, K. Agho, O. Ezeh, A. Renzaho, M. Dibley, and C. Raynes-Greenow, "Under-five mortality and associated factors: evidence from the Nepal demographic and health survey (2001-2016)," International Journal of Environmental Research and Public Health, vol. 16, no. 7, p. 1241, 2019.

[38] A. S. Susuman, "Child mortality rate in Ethiopia," Iranian Journal of Public Health, vol. 41, no. 3, pp. 9-19, 2012.
[39] D. Bedada, "Determinant of under-five child mortality in Ethiopia," American Journal of Theoretical and Applied Statistics, vol. 6, no. 4, pp. 198-204, 2017.

[40] J. O. Oloo, "Child mortality in developing countries: challenges and policy options," Eastern Africa Social Science Research Review, vol. 21, no. 2, pp. 1-7, 2005.

[41] National Planning Commission and The Federal Democratic Republic of Ethiopia, "The second growth and transformation plan (GTP II), 2015/16-2019/20: NPC Addis Ababa, Ethiopia," 2016, http://dagethiopia.org/new/docstation/com.content. article/100/gtpii.english.translation.final.june.21,2016.pdf. 